\title{
Roadside Safety Recovery Zone Corridor Widths Derived from Live Field Experiments and Comparison to Past Accidents Records
}

\author{
${ }^{1 *}$ A.K.Kunji, ${ }^{2}$ A.Kusbiantoro, ${ }^{2}$ A.Zulkiple and ${ }^{1}$ H.M.Ramli \\ ${ }^{I}$ Perunding RJA, 25100, Kuantan, Pahang, Malaysia \\ ${ }^{2}$ Faculty of Engineering Technology, University Malaysia Pahang, 26300, Kuantan, Pahang, Malaysia \\ *Corresponding Author: kamaliem12@gmail.com
}

\begin{abstract}
The increasing number of run-off-road accidents has driven institutions to study and introduce roadside geometric design guidelines to reduce the number of fatalities and severe injuries. Providing the right configuration and dimensions of a roadside slope cross section would allow travel lane motorists who have strayed off the travel lane with a safe way of traversing back into driving lanes and can reduce run-off-road fatal accidents or severe injuries. American Association of Highway and Transportation Official (AASHTO) introduced roadside safety clear zone derived from a set of past accident records. Unfortunately, most of other countries do not keep the same past accident records. Alternatively, safety clear zone can be derived from live field experiments. The 180 live field experiments were safely performed by five drivers with three motorcars at ten locations having various roadside slope gradients and ground surface conditions. The motorcar tires' printed marks on the turfed roadside were measured, recorded, and analyzed to establish a safety clear zone corridor size. Comparatively, the American figures are higher as they have accounted for additional widths of nonrecovery zone and turn out area, the justifiable difference confirms that deriving roadside safety recovery zone corridor widths by the method of live field experiments is a sound engineering practice. The study concludes that the live field experiment method can be applied in place of past accident records in establishing the size of roadside safety clear zones.
\end{abstract}

Indexed Terms- Road accident, roadside slope, safety recovery zone.

\section{INTRODUCTION}

Throughout $2001-2010$, there were 32\% single vehicles crashes recorded by European Union and 42\% of it were happened off-road and resulted in fatal crashes [1-3]. In addition, United States also recorded an approximately of $60 \%$ single-vehicles crashes that took place on the shoulder, median, or off the roadway $[4,5]$. The accidents normally lead to fatal crashes due to high crash impacts resulting from a combination of high travelling speed, a steep roadside slope gradient, and obstructions such as trees, utilities, sign poles and drainage structures. Realizing the situation, for over 30 years, United States of America (USA) has introduced roadside geometric design guidelines that require the provision of a roadside safety clear zone corridor that consists of an area comprising a road shoulder, roadside recoverable slope, a non-recoverable slope, and a clear-run-out area at the bottom of the slope [6]. Conceptually, roadside safety clear zone corridors provide space for errant drivers to gain a second chance to save their lives by traversing back into the carriageway upon skidding. The introduction of a $9 \mathrm{~m}$ or greater roadside safety recovery zone corridor in the United States permits $80 \%$ of run-off-road errant vehicles to recover and move back into driving lanes [6, 7]. 


\subsection{Causes of Roadside Accidents.}

It is very common for vehicles leaving the carriageway and encroaching into roadside due to fatigue, bad handling at very high speed, influenced by alcohol or drugs, slippery road condition due to rain or snow, poor vehicle condition and driving with visibility restriction due to poor road design [8]. Distraction has great impact to driving safety and distraction due to multitasking such as the use of mobile phone while driving is among the popular cause of accidents [9-14]. The recent experiments of 241 drivers driving for 43,000 hours while using mobile phones showed increased number of crashes as compared to other distractions $[14,15]$.

\subsection{Concept and Characteristics of Roadside Safety Clear Zone Corridor}

The safety clear zone corridor width (herein denoted as ' $Z$ ') is defined as a width adjacent to the travel way measured perpendicularly and horizontally from the edge of the carriageway as shown in Figure 1, that is clear of fixed objects and has a slope gradient of $1 \mathrm{~V}: 4 \mathrm{H}$ or gentler. The limitation of the permissible maximum roadside slope gradient of $1 \mathrm{~V}: 4 \mathrm{H}$ is based on the American study that a steeper slope will encounter traversal problems [6]. The obstruction free corridor allows the uninterrupted passage of skidding vehicles in traversing back to the travel lane. The geometric design requirement for the roadside safety clear zone corridor area is that once the area is encroached, an errant driver can maneuver his vehicle back to the travel lane to save his life. If the situation is in the recovery mode, then we address it as a forgiving roadside geometric design. It is hard to deduce the correlation between influencing factors and fatalities [16]. The road shoulder is a component of the roadside, and its width and type have played a key role in roadway safety $[17,18]$. Forgiving roadside geometric designs are composed of two main elements: a generous roadside corridor space that is free of obstruction and a gentle roadside slope gradient. Zegeer et al., (1988) reported that for generally unobstructed flat ground, a provision of 1.5 to 6.2 meters for the roadside safety recovery corridor width might reduce accident rates from 13 to $44 \%$ [19]. The focus of this research is to establish the relationship between the size of the roadside safety clear zone corridor with the roadside slope gradient and vehicle travelling speed.

\section{RESEARCH APPROACH}

\subsection{Method}

The most scientific of all methods is an experimental method. The experimental method eliminates problem in lack of control over situation, as often encounter in non-experimental method. It is a study of cause and effect, which overcome the deliberate manipulation of one variable, while trying to keep all other variables constant as in the case of non-experimental method.

\subsubsection{Selection of Vehicle Types}

The Malaysian statistic from the year 2007 through 2010 for passenger vehicles having fatalities with three and above fatalities and commercial vehicles with one fatality and above recorded that passenger cars represent dominant vehicle with fatal accidents [20]. Thus, four wheels vehicle or motorcars were used for the field driving test works.

\subsubsection{Selection of Driving Test Sites}

Test locations were selected from areas of low traffic volume of not more than a car in about 30 seconds to a minute to ensure the safety of the public and driver. The count on traffic interval duration is to allow for the test car to skid and recover back to the travel lane with oncoming approaching car in the range of beyond 200 metres. There shall not be any nearby drain in any form, unless drain that is small enough to be traversable during of emergency situation. Within a period of five months, the team comprise of five members found 10 suitable test sites for the live field experiments.

There were four elements criteria in selecting the roadside geometric design that suit the test site requirements as follows: 
The roadside slope gradient to be gentler than $1 \mathrm{~V}: 4 \mathrm{H}$ as any slope steeper than this will not permit most vehicles to recover back to travel lane as quoted under Clause 3.2.1 of Roadside Design Guide [6]. Hence, the favorable slopes are between $1 \mathrm{~V}: 5 \mathrm{H}$ to $1 \mathrm{~V}: 4 \mathrm{H}, 1 \mathrm{~V}: 6 \mathrm{H}$ to $1 \mathrm{~V}: 5 \mathrm{H}, 1 \mathrm{~V}: 7 \mathrm{H}$ to $1 \mathrm{~V}: 6 \mathrm{H}$ and $1 \mathrm{~V}: 8 \mathrm{H}$ to flatter.

Roadside corridor of sufficiently broad is essential to ensure practicability and safety for the testing work. The roadside corridor width between 6 to 10 metres measured horizontally and perpendicularly away from the carriageway, and stretching 50 metres along the road are adequate for the vehicle running test. A few trial runs before an actual 5 round tests at each speeds are useful to ensure consistent results.

The test area is to be unobstructed and traversable i.e. free of fixed objects such as trees, lamppost, signboard post or the like. The ground surface shall be evenly level without pot holes and bumps. Any bump will cause the vehicle to be airborne.

\subsubsection{Selection of Test Speeds}

Selection of vehicle travelling speeds for the driving tests is based on design speeds. The American and Malaysian design speeds are in the range of $60 \mathrm{~km} / \mathrm{h}$ to $110 \mathrm{~km} / \mathrm{h}$. However, the test speed of $50 \mathrm{~km} / \mathrm{h}$ is included to give better profile to the graph.

Taking into consideration the available site condition and the safety of the driver the approach taken were as follows:

The vehicle test speed will be from $50 \mathrm{~km} / \mathrm{h}$ to $90 \mathrm{~km} / \mathrm{h}$ in the interval of $10 \mathrm{~km} / \mathrm{h}$. The safety recovery zones corridor widths for the speed of 100 and $110 \mathrm{~km} / \mathrm{h}$ will be obtained by interpolation as to minimise danger to the driver if execute the tests at high speed. However, any tests could not be carried out below $100 \mathrm{~km} / \mathrm{h}$, the result will be obtained by interpolation.

\subsubsection{Selection of Vehicle's Exit Angle (Encroachment Angle)}

The vehicle's exit angle or also known as encroachment angle is the angle at which the errant vehicle stray off from travel lane and get into the roadside. The popular theories on determining the vehicle exit angle are by application of formula and statistical study based on past accident records. In carrying out live field experiment, the vehicle's exit angle plays an important role due to its influence to the size roadside safety recovery zone corridor at a given roadside embankment's slope.

Generally, angle of exit for errant vehicle strayed off from the road for run-off-road case will depend on many factors such as road-tire friction, condition of car tire alignment and camber, travel speed, lateral position of vehicle against edge of road, road geometric design, vehicle type, road camber (cross-slope), driver's skill etc. The choice of vehicle's exit angle for the field experimental study is between the applications of theoretical formula presented in the NCHRP Report 492 [21] or value generated from the study of accidents records by Sicking and Ross [22].

The formula presented in the NCHRP report 492 (2003) gives,

$\theta_{c}=\cos ^{-1}\left(1-S_{o} g f_{m} / V^{2}{ }_{c}\right.$

where:

$\theta c:$ maximum vehicle's encroachment (exit) angle

$\mathrm{Vc}$ : encroachment speed

So : vehicle offset from edge of pavement (also denotes as d)

$\mathrm{fm}$ : maximum available friction coefficient

$\mathrm{g}:$ acceleration of gravity

Determination of vehicle's exit angle based on accidents record has many variables with some of them unknown parameters. The variables comprise of drivers, vehicles, site conditions, speed etc. One of the unknown but most important parameter is the actual speed of the vehicle at the time of accident. The 
speed is the major concern as vehicle's exit angle varies inversely with speed of vehicle on encroachment into roadside [21].

Referenced to Figure 1 generated from the Table 1, suggest the vehicle's exit angle that is most probable based on $70 \%$ of run-off-road cases is less than 20 degrees. The 20 degrees vehicle's exit angle was employed for the live field experiments in deriving the roadside safety recovery zone corridor widths for various roadside slope gradients. Application of vehicle's exit angle based on past accident records is a better choice as it was produced from a real life situation and was adopted for the experimental study.

Table 1: Vehicle's Exit Angle versus Cumulative Percentage (From Published Report PPR 298, May 2005 with permission from TRL Limited) [23]

\begin{tabular}{lllllll}
\hline Vehicle's Exit Angle $\theta$ (degree) & 5 & 15 & 25 & 35 & 45 & 90 \\
Cumulative percentage P \% & 10 & 55 & 83 & 94 & 98 & 100 \\
\hline
\end{tabular}

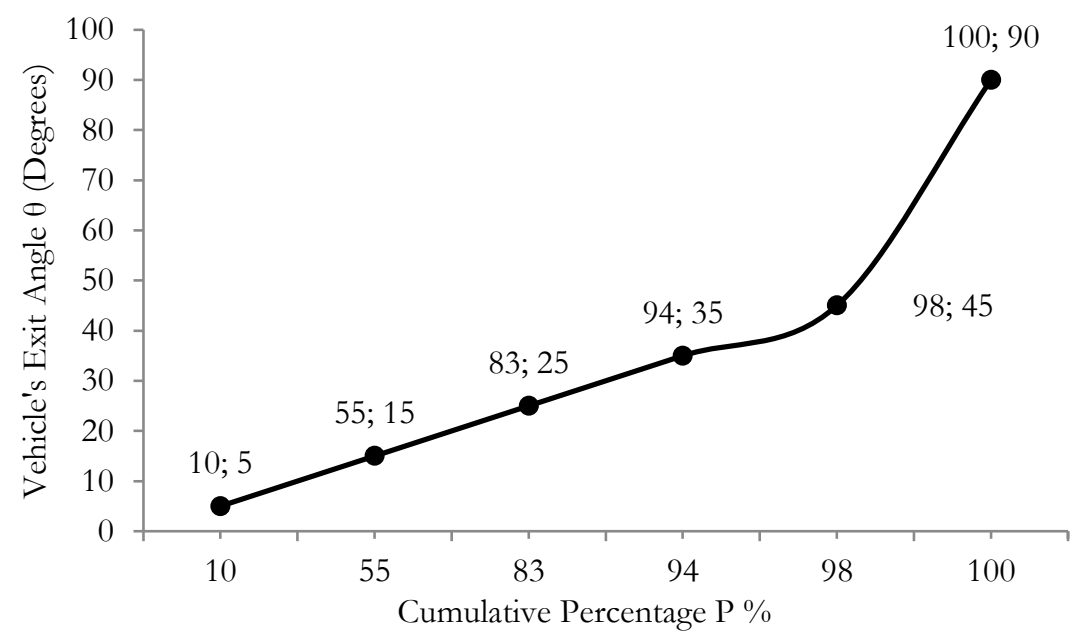

Figure 1: Vehicle's Exit Angle Versus Cumulative Percent

\section{DATA COLLECTION AND ANALYSIS}

All data collected from the ten field experiments was compiled and plotted with software, and a sample for Pantai Sepat, Kuantan, Pahang, is shown in Table 2 and Figure 2. The scattered coordinates on the graph indicate reactions of differing traversing paths have different ground surface condition, surface sand particles density, grass intensity and textures, and influence to various driver reactions when traversing back to the travel lane. The graphical line and its equation represent a statistical relationship between the safety clear zone corridor width $Z$ and the vehicle travelling speed $V$ at a given foreslope gradient $S$. Computing the safety clear zone corridor widths $Z$ with the software generated statistical trend line equations in Figure 2 and the other nine figures from different sites for vehicle speeds ranging from 50 through $110 \mathrm{~km} / \mathrm{h}$, the results obtained are summarized in Table 3 . The values of the roadside slope gradients $S$ shown in the table are in decimal form and were reconfigured to bold numbers (nondecimal) of $1 \mathrm{~V}: 4 \mathrm{H}$ through $1 \mathrm{~V}: 10 \mathrm{H}$ so as to be in line with the industry's practice that requires bold figures to ease construction work. Configuring roadside foreslope gradient $S$ in bold numbers (nondecimal) was accomplished by re-plotting the values in Table 4 to produce new generalized equations of $Z, S$ and $V$. 
Table 2: Field Experimental Results at Pantai Sepat

Field Experiments Results for Roadside Fore-Slope Gradient of 1V:7.1H at Km 35 KuantanPekan Highway, Pekan, Pahang

\begin{tabular}{|c|c|c|c|c|c|c|}
\hline \multirow{2}{*}{$\begin{array}{c}\text { Speed } \\
(\mathrm{km} / \mathrm{h})\end{array}$} & \multicolumn{6}{|c|}{ Safety Recovery Zone Corridor Width Z (m) } \\
\cline { 2 - 7 } & Test 1 & Test 2 & Test 3 & Test 4 & Test 5 & Average \\
\hline 50 & 2.5 & 2.5 & 2.5 & 2.5 & 2 & 2.4 \\
\hline 60 & 2.8 & 2.8 & 3.2 & 2.8 & 2.8 & 2.9 \\
\hline 70 & 3 & 3.2 & 3.3 & 3 & 3 & 3.1 \\
\hline 80 & 3.5 & 3.4 & 4 & 4.5 & 4.5 & 4 \\
\hline 90 & 5 & 5 & 5.3 & 5.3 & 5.3 & 5.2 \\
\hline
\end{tabular}

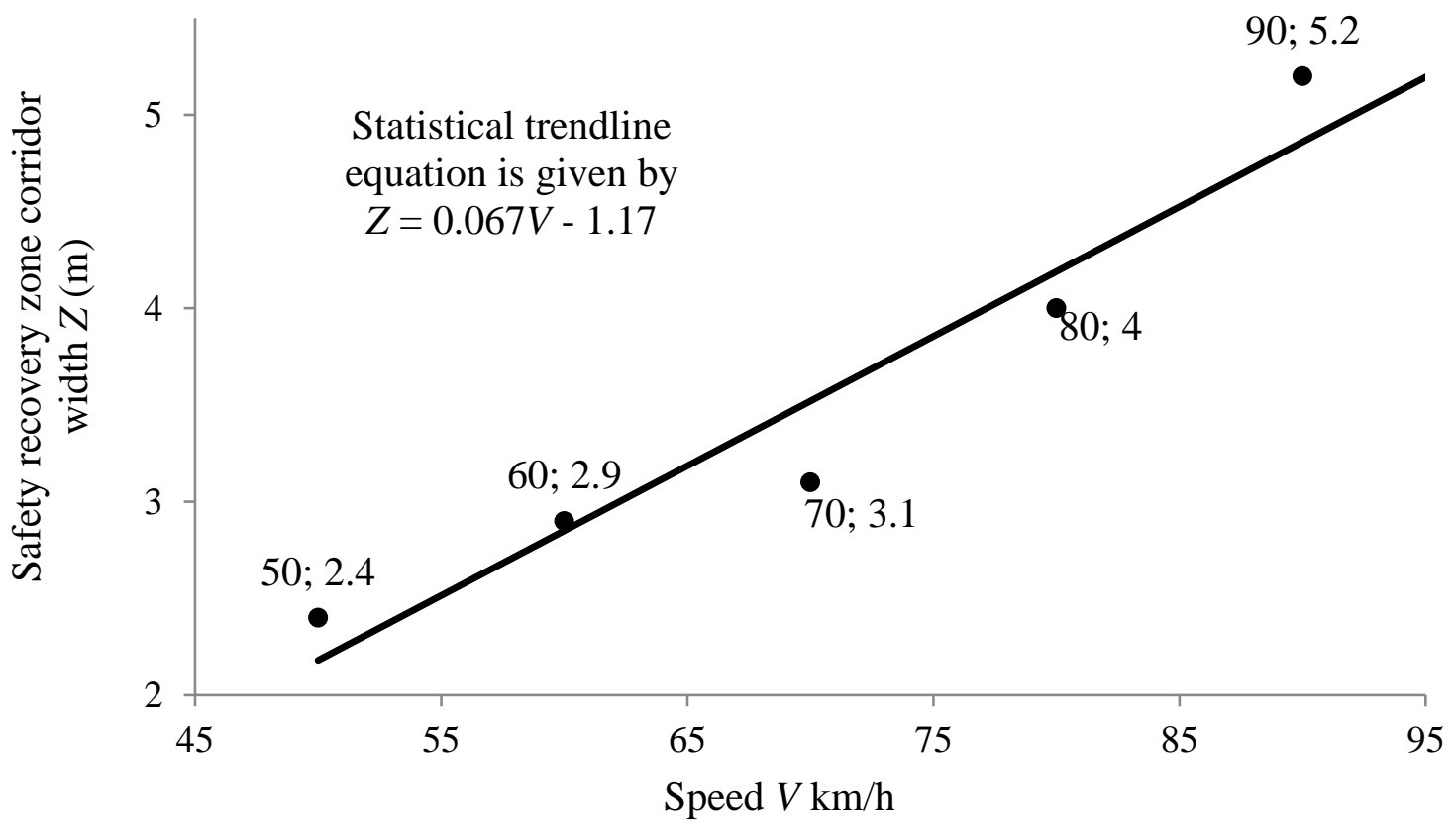

Figure 2: Roadside safety clear zone widths $Z$ versus vehicle speeds $V$ for roadside foreslope gradient $S$ 1V:7.1H at Pantai Sepat, Kuantan, Pahang 
Table 3: Roadside safety clear zone widths $Z$, in meters, for various speeds $V$ and roadside fore-slope gradients $S$.

\begin{tabular}{|c|c|c|c|c|c|c|c|c|c|c|}
\hline \multirow[b]{2}{*}{ 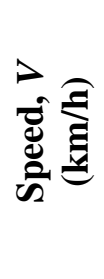 } & \multicolumn{10}{|c|}{ Roadside Fore-Slope Gradient, $S$} \\
\hline & 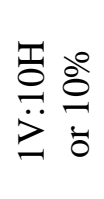 & 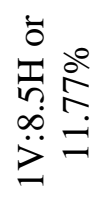 & 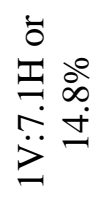 & 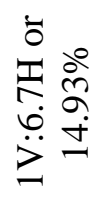 & 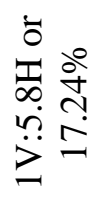 & 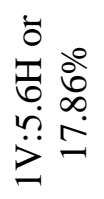 & 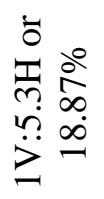 & 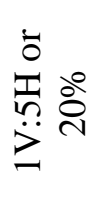 & 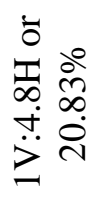 & 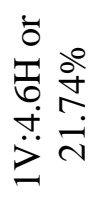 \\
\hline 50 & 1.66 & 2.12 & 2.18 & 2.68 & 2.78 & 3.17 & 3.32 & 3.48 & 3.52 & 3.92 \\
\hline 60 & 2.34 & 2.82 & 2.85 & 3.43 & 3.53 & 3.87 & 4.10 & 4.05 & 4.19 & 4.54 \\
\hline 70 & 3.01 & 3.53 & 3.52 & 4.18 & 4.28 & 4.57 & 4.62 & 4.62 & 4.86 & 5.16 \\
\hline 80 & 3.69 & 4.23 & 4.19 & 4.93 & 5.03 & 5.27 & 5.31 & 5.19 & 5.53 & 5.78 \\
\hline 90 & 4.36 & 4.93 & 4.86 & 5.68 & 5.78 & 5.97 & 5.96 & 5.76 & 6.2 & 6.4 \\
\hline 100 & 5.03 & 5.63 & 5.53 & 6.43 & 6.53 & 6.67 & 6.61 & 6.33 & 6.87 & 7.02 \\
\hline 110 & 5.71 & 6.33 & 6.20 & 7.18 & 7.28 & 7.37 & 7.26 & 6.90 & 7.54 & 7.64 \\
\hline
\end{tabular}

Re-plotting the values in Table 3 produced a set of trend line statistical equations for vehicle speeds of 50 through $110 \mathrm{~km} / \mathrm{h}$ as shown in Figures 2 through 8 . Based on the equations, the calculated refined values of the safety clear zone corridor widths $Z$ versus the vehicle travelling speeds $V$ and varying roadside slope gradients $S$ in bold numbers are shown in Table 5. Roadside slope gradients $S$ that were steeper than $1 \mathrm{~V}: 4 \mathrm{H}$ were not applied in producing Table 5 as these ranges of slopes are classified as non-recoverable or non-traversable by skidding vehicles [6]. 


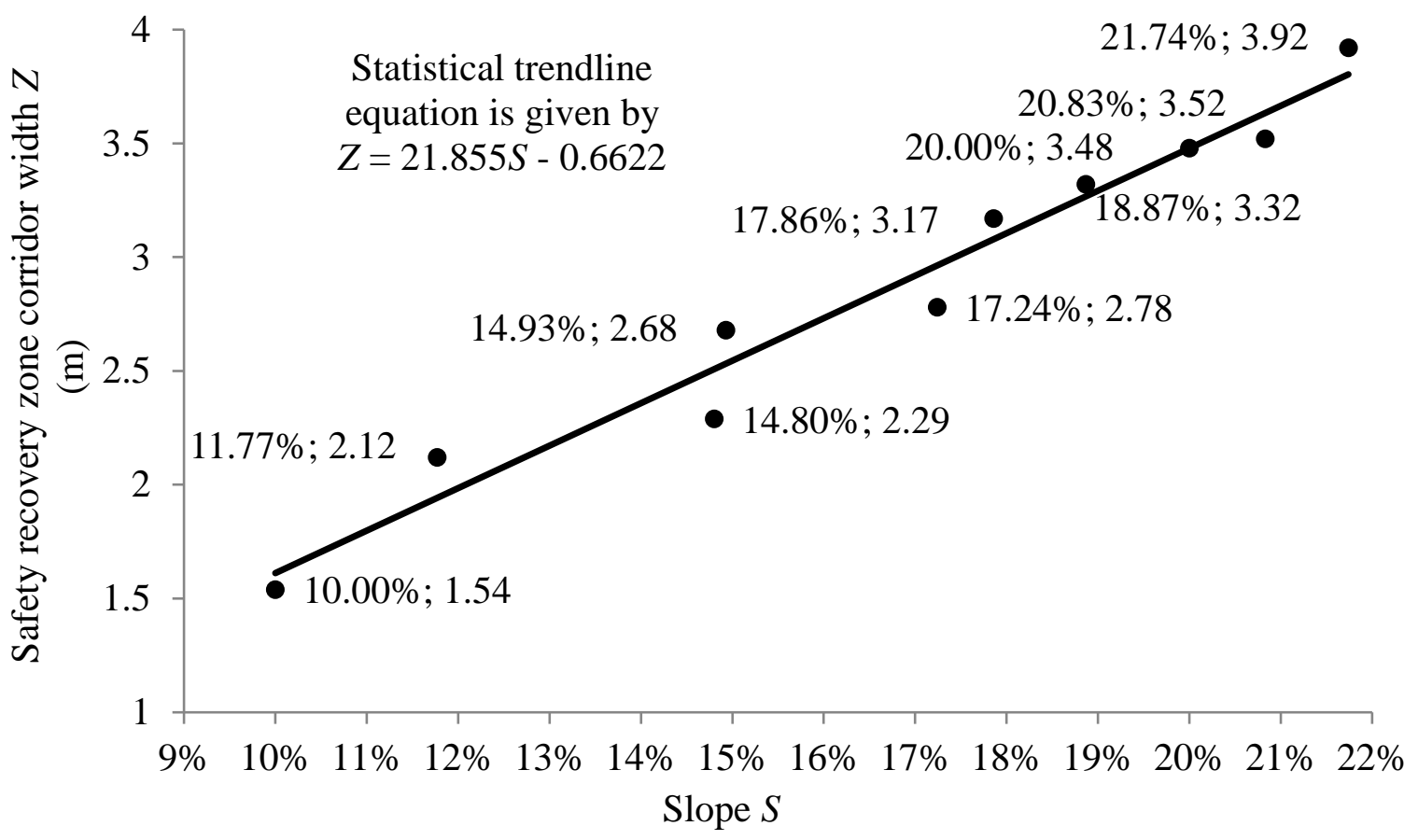

Figure 3: Roadside safety clear zone widths $Z$ versus roadside fore-slope gradients $S$ at vehicle travelling speed of $50 \mathrm{~km} / \mathrm{h}$.

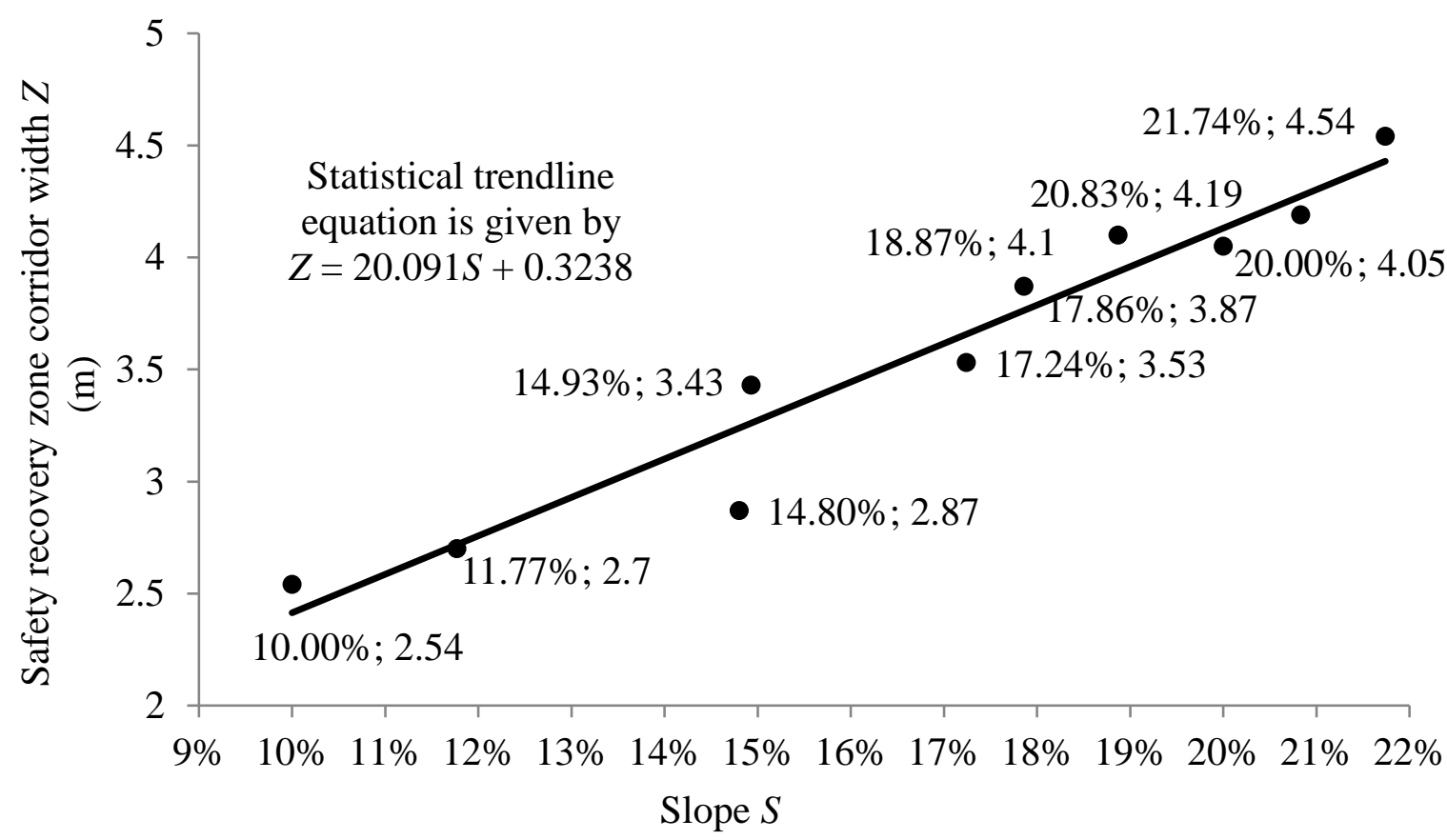

Figure 4: Roadside Safety Clear Zone Widths $Z$ versus Roadside Foreslope Gradients $S$ at Vehicle Travelling Speed of $60 \mathrm{~km} / \mathrm{h}$ 


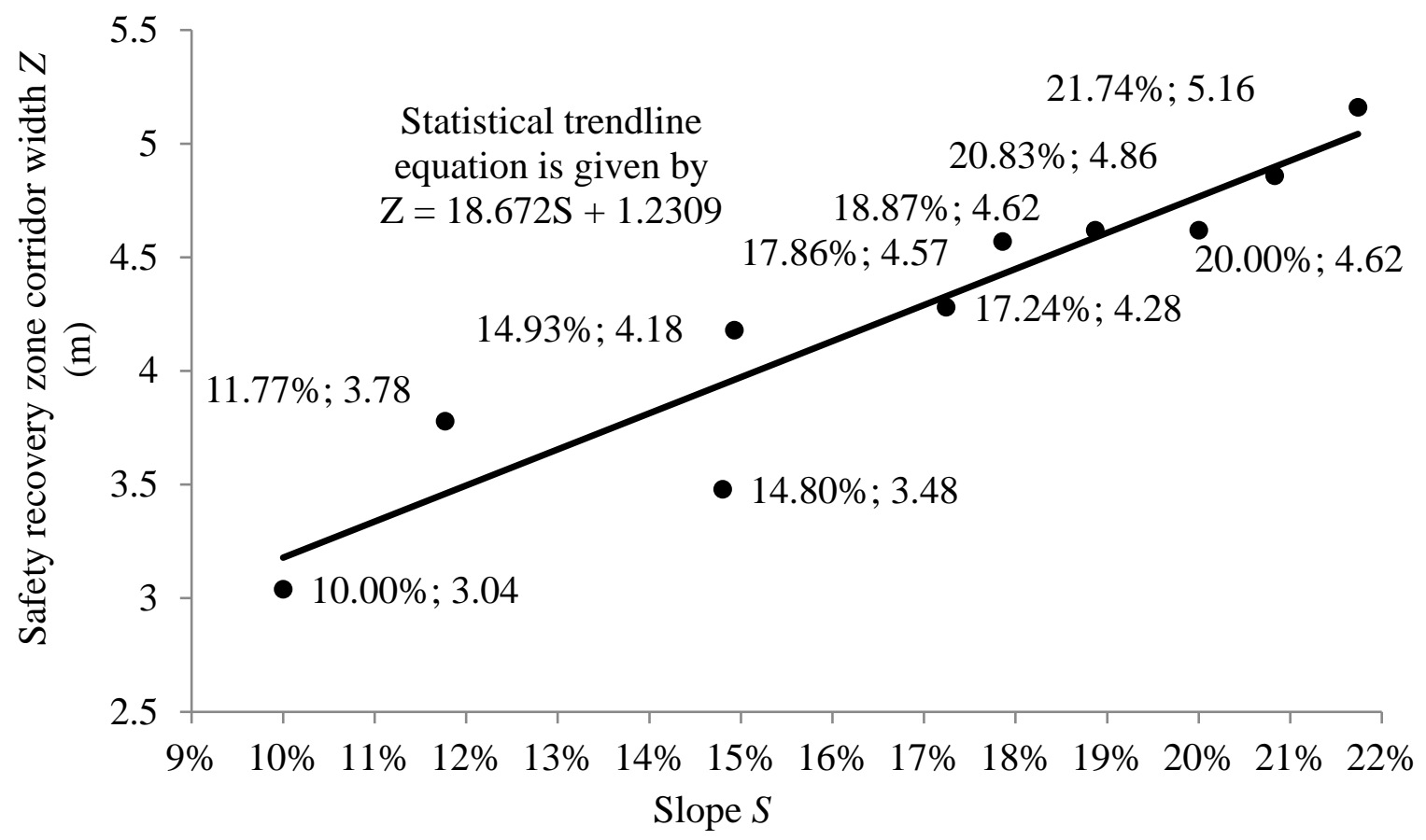

Figure 5: Roadside Safety Clear Zone Widths $Z$ versus Roadside Foreslope Gradients $S$ at Vehicle Travelling Speed of $70 \mathrm{~km} / \mathrm{h}$

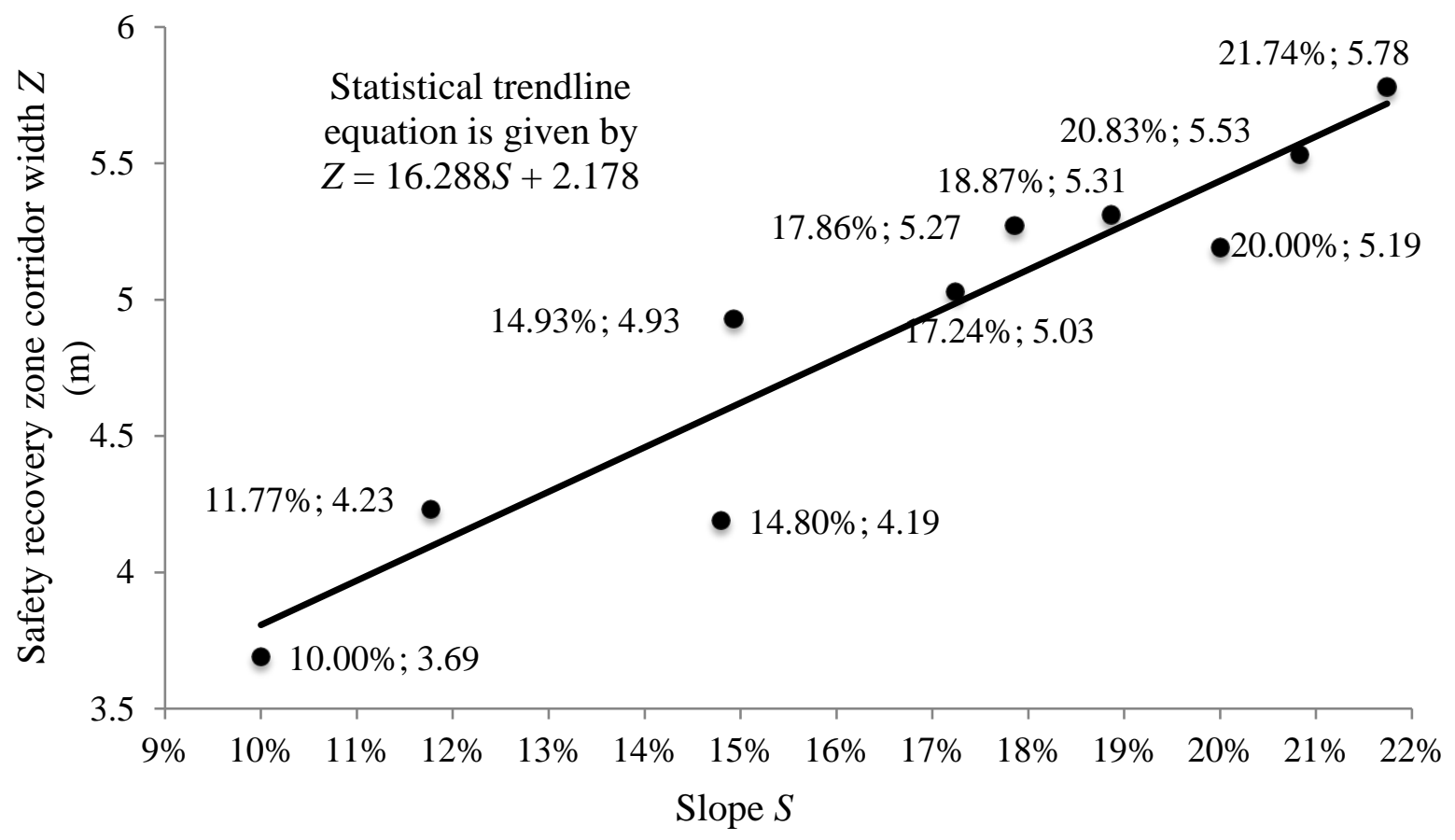

Figure 6: Roadside Safety Clear Zone $Z$ versus Roadside Foreslope Gradients $S$ at Vehicle Travelling Speed of $80 \mathrm{~km} / \mathrm{h}$ 


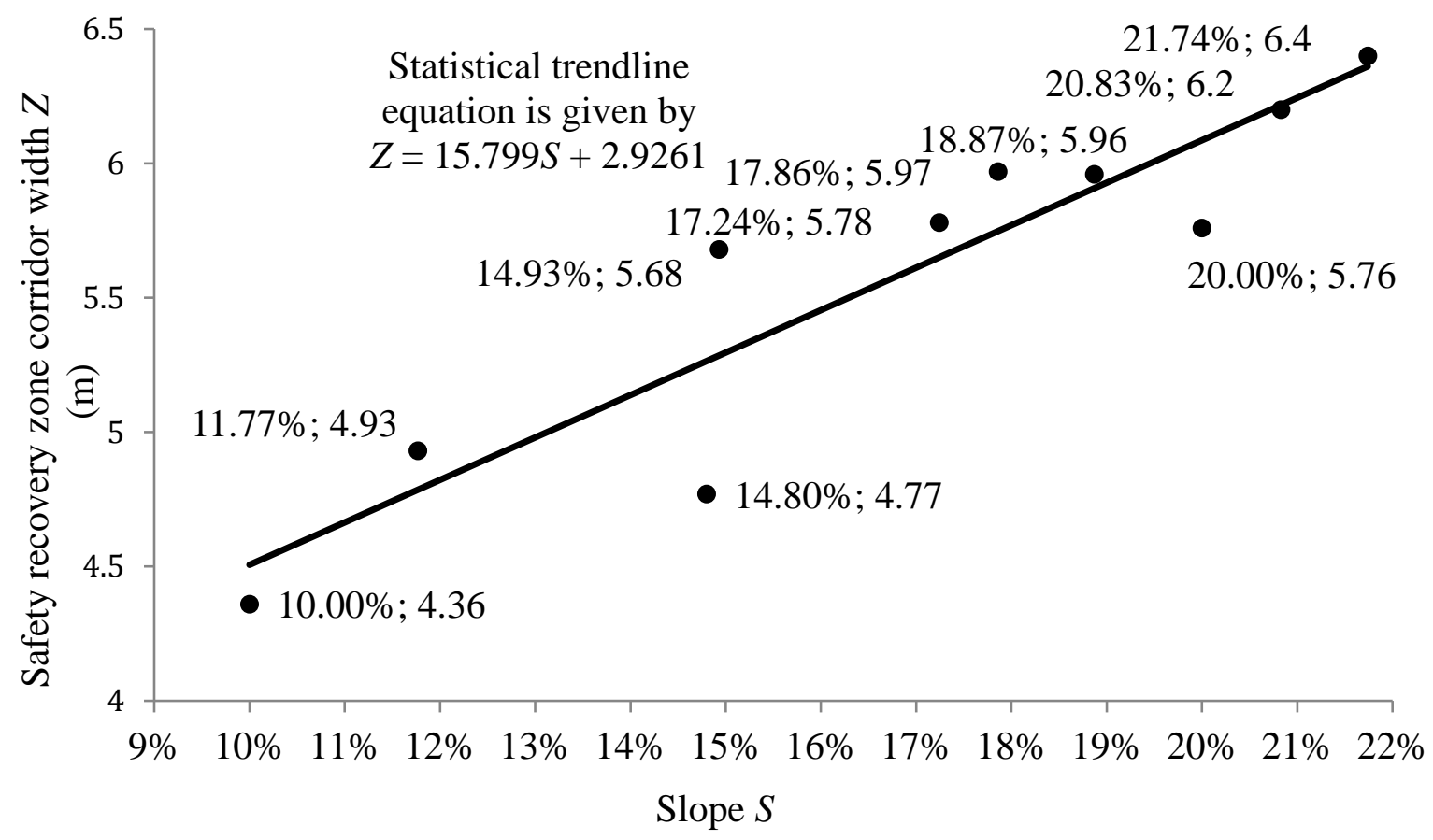

Figure 7: Roadside Safety Clear Zone Widths $Z$ versus Roadside Fore-Slope Gradients $S$ at Vehicle Travelling Speed of $90 \mathrm{~km} / \mathrm{h}$

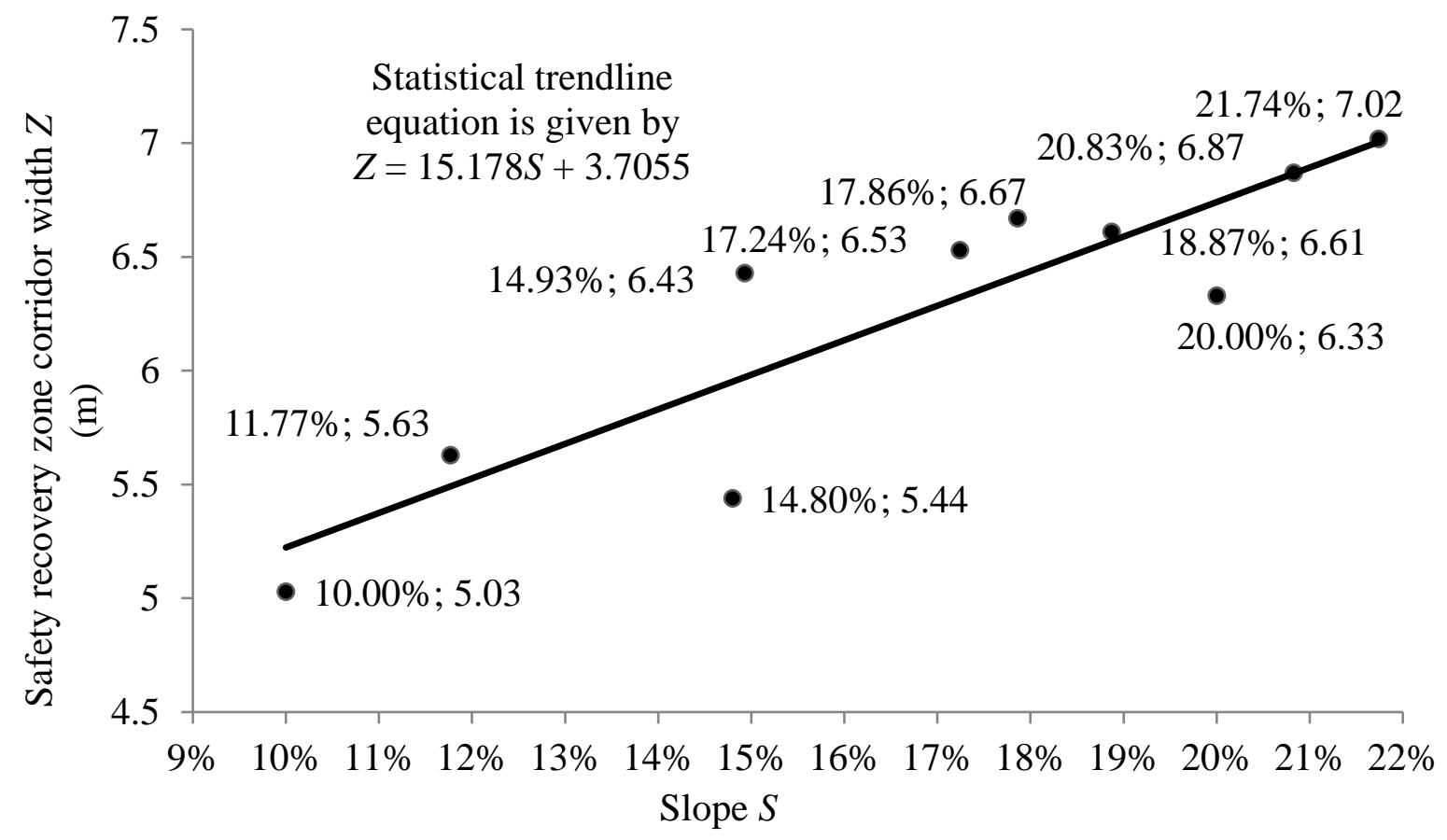

Figure 8: Roadside Safety Clear Zone Widths $Z$ versus Roadside Foreslope Gradients $S$ at Vehicle Travelling Speed of $100 \mathrm{~km} / \mathrm{h}$ 


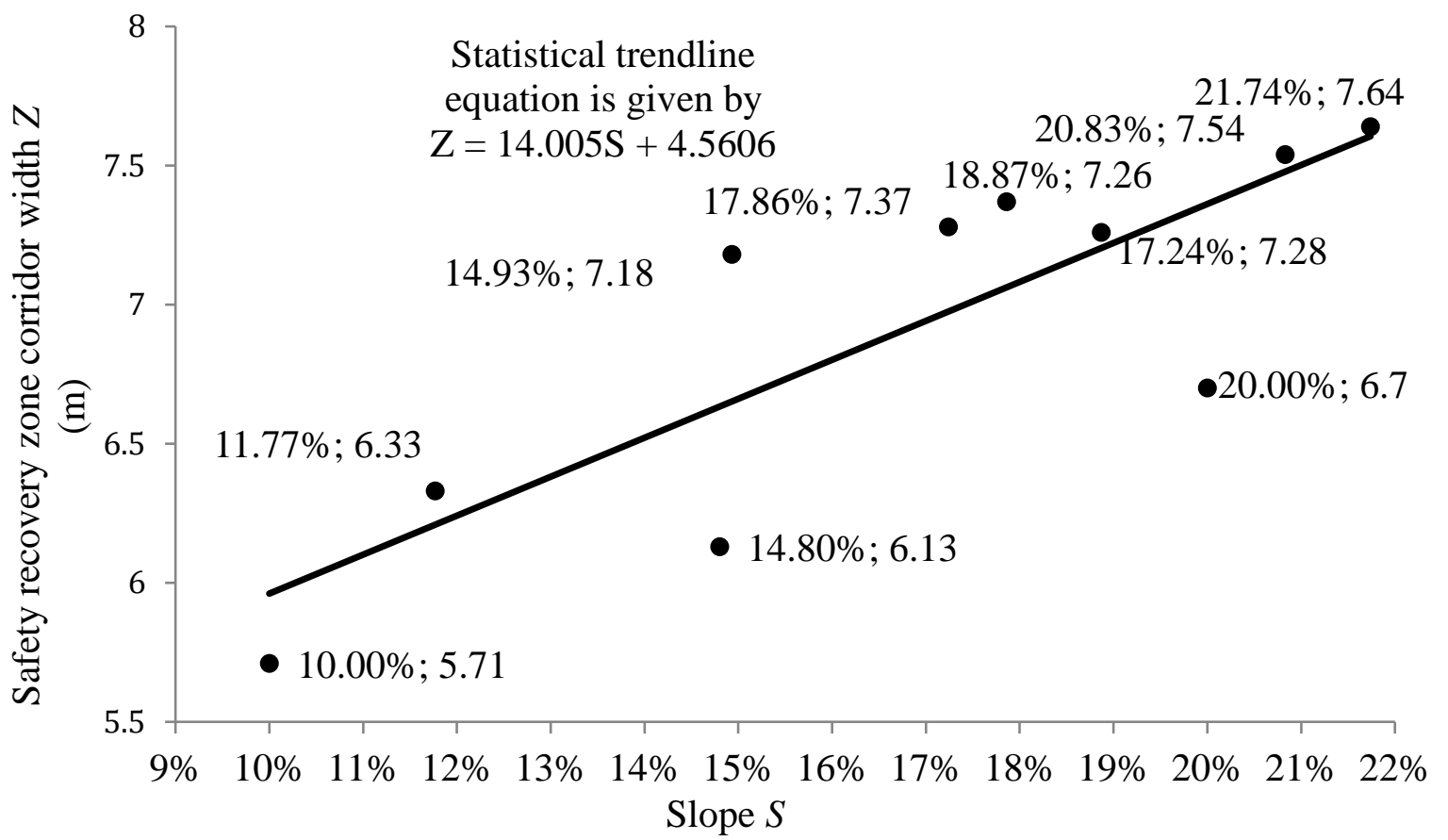

Figure 9: Roadside Safety Clear Zone Width $Z$ versus Roadside Fore-Slope Gradients $S$ at Vehicle Travelling Speed of $110 \mathrm{~km} / \mathrm{h}$

Table 4: Roadside Safety Clear Zone Widths $Z$ for Specified Roadside Slope Gradients $S$ at Various Vehicle Speeds $V$ with $S$

\begin{tabular}{|c|c|c|c|c|c|c|c|}
\hline \multirow{2}{*}{ 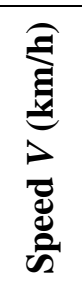 } & \multicolumn{7}{|c|}{ Safety Recovery Zone Corridor Width $Z$ (m) } \\
\hline & 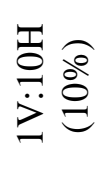 & 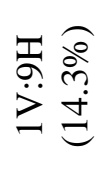 & 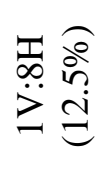 & 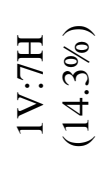 & 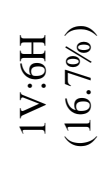 & 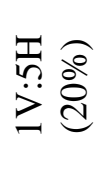 & 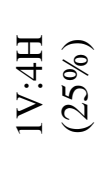 \\
\hline 50 & 1.52 & 1.77 & 2.07 & 2.46 & 2.98 & 3.71 & 4.80 \\
\hline 60 & 2.33 & 2.56 & 2.84 & 3.19 & 3.67 & 4.34 & 5.35 \\
\hline 70 & 3.10 & 3.31 & 3.56 & 3.90 & 4.34 & 4.97 & 5.90 \\
\hline 80 & 3.71 & 3.90 & 4.14 & 4.45 & 4.86 & 5.44 & 6.31 \\
\hline 90 & 4.51 & 4.68 & 4.90 & 5.18 & 5.56 & 6.09 & 6.88 \\
\hline 100 & 5.22 & 5.39 & 5.60 & 5.87 & 6.24 & 6.74 & 7.50 \\
\hline 110 & 5.96 & 6.12 & 6.31 & 6.56 & 6.89 & 7.36 & 8.06 \\
\hline
\end{tabular}




\section{CONCLUSIONS}

The outcome of the study shows that the live field experiment method is a safe and reliable method in deriving the size of roadside safety recovery zone for various vehicle travelling speeds and roadside slope gradients. Observation from the live field experiments recommends that for adequate safety ensure that the roadside has ample free space for vehicle turning and skidding on traversing to account for slippery slope contributed by loose turf, poor car condition, unexpected driver reaction and sand accumulation on the ground surface.

The tested roadside safety clear zone corridor widths $Z$ range between 1.52 to 8.06 meters for speed limits between 50 and $110 \mathrm{~km} / \mathrm{h}$ and for roadside slope gradients between $1 \mathrm{~V}: 10 \mathrm{H}$ and $1 \mathrm{~V}: 4 \mathrm{H}$. For the roadside gentler than $1 \mathrm{~V}: 10 \mathrm{H}$, the safety recovery zone corridor size may adopt the same values for $1 \mathrm{~V}: 10 \mathrm{H}$.

The discovered relationships between the safety clear zone corridor widths $Z$ and roadside slope gradients $S$ for various vehicle design speeds are as follows:

- For design speed $50 \mathrm{~km} / \mathrm{h}, \mathrm{Z}=21.855 \mathrm{~S}-0.6622$

- $\quad$ For design speed $60 \mathrm{~km} / \mathrm{h}, \mathrm{Z}=20.091 \mathrm{~S}+0.3238$

- For design speed $70 \mathrm{~km} / \mathrm{h}, \mathrm{Z}=18.672 \mathrm{~S}+1.2309$

- For design speed $80 \mathrm{~km} / \mathrm{h}, \mathrm{Z}=17.326 \mathrm{~S}+1.9746$

- For design speed $90 \mathrm{~km} / \mathrm{h}, \mathrm{Z}=15.799 \mathrm{~S}+2.9261$

- For design speed $100 \mathrm{~km} / \mathrm{h}, \mathrm{Z}=15.178 \mathrm{~S}+3.7055$

- For design speed $110 \mathrm{~km} / \mathrm{h}, \mathrm{Z}=14.055 \mathrm{~S}+4.5606$

The equations establish the fact that the safety clear zone corridor widths $\mathrm{Z}$ increase with the increase of the roadside slope gradients $\mathrm{S}$ at all vehicle-travelling speeds $\mathrm{V}$. The above equations are applicable for design engineer to calculate roadside safety recovery zone corridor width for any particular vehicle design speed and roadside slope gradient.

Depending on the roadside design geometries, the roadside safety clear zone corridor widths derived from field experiments, for flat terrain roads range from 3.5 to 8.06 meters for vehicle travelling speeds between 60 and $110 \mathrm{~km} / \mathrm{h}$ for roadside foreslopes gradients between $1 \mathrm{~V}: 6 \mathrm{H}$ and $1 \mathrm{~V}: 4 \mathrm{H}$. At design Average Daily Traffic of 1,500-6,000 and above 6,000, for vehicle travelling speeds between 60 and $110 \mathrm{~km} / \mathrm{h}$, these figures are about $0 \%$ to $38 \%$ and $22.22 \%$ to $42.43 \%$ lower than the AASHTO suggested with clear zone ranging from 3.5 to 13.0 and 4.5 to 14 meters respectively. Comparatively, the American figures are higher as they have accounted for additional widths of non-recovery zone and turn out area, the justifiable difference confirms that deriving roadside safety recovery zone corridor widths by the method of live field experiments is a sound engineering practice.

The study suggests that as far as practicable, all existing trees, utility poles, and signs to be relocated outside the roadside safety clear zone corridor specified. In a situation where the relocation of the existing obstructing objects is not possible, provide treatment such as fixing breakaway devices, installing shielding, or installing crash cushions. Additionally, wherever practicable, existing roadside slope gradients that are steeper than $1 \mathrm{~V}: 4 \mathrm{H}$ should be readjusted to a gentler gradient to reduce accident impact, which may minimize the level of injury and fatality. Finally, the introduction of a safety clear zone corridor chapter in the future design guideline will drive toward a forgiving roadside geometric design that saves human lives. 


\section{REFERENCES}

[1] Carlos Roque, Filipe Moura, João Lourenço Cardoso. "Detecting unforgiving roadside contributors through the severity analysis of ran-off-road crashes". Accid. Anal. Prev. 80, 262273, 2015

[2] European Road Safety Observatory. "Traffic Safety Basic Facts 2012: Single Vehicle Accidents". 2012

[3] National Highway Traffic Safety Administration. "NCSA Data Resource Website: Fatality Analysis Reporting System (FARS) Encyclopedia". 26 August 2014

[4] Freeman P., Neyens D. M., Wagner J., Switzer F., Alexander K., Pidgeon P. "A video based runoff-road training program with practice and evaluation in a simulator". Accid. Anal. Prev. 82, 19,2015

[5] National Highway Traffic Safety Administration. "Traffic Safety Facts 2011: A Compilation of Motor Vehicle Crash Data from the Fatality Analysis Reporting System and the General Estimates System". Department of Transportation, Washington, D.C. 2011

[6] American Association of State Highway and Transportation Officials. "Roadside design guide 4th. Edition". 2011

[7] Graham J.L. and Hardwood D.W. "Effectiveness of Clear Recovery Zones. National Cooperative Highway Research Program Report 247". National Cooperative Highway Research Program Transportation Research Board. 1982

[8] Brockenbrough R. L., Boedecker K. J. "Highway Engineering Handbook". McGraw-Hill Professional; 2 edition. 2003

[9] Chen Z., Wu C., Zhong M., Lyu N., Huang Z. "Identification of common features of vehicle motion under drowsy/distracted driving: A case study in Wuhan, China". Accid. Anal. Prev. 81, 251-259, 2015

[10] Jennie Connor, Robyn Norton, Shanthi Ameratunga, Elizabeth Robinson, Ian Civil, Roger Dunn, John Bailey, Rod Jackson. "Driver sleepiness and risk of serious injury to car occupants: population based case control study". Brit. Med. Jour. 324 (7346), 1125, 2002

[11] Thiffault P., Bergeron J. "Monotony of road environment and driver fatigue: a simulator study". Accid. Anal. Prev. 35, 381-391, 2003

[12] Wilson, F. A., Stimpson, J. P. "Trends in fatalities from distracted driving in the United States 1999-2008". Am. J. Public Health. 100(11), 2213-2219, 2010

[13] Hallvig D., Anund A., Fors C., Kecklund G., Karlsson J. G., Wahde M., Akerstedt T. "Sleepy driving on the real road and in the simulator - a comparison". Accid. Anal. Prev. 50, 44-50, 2013

[14] Saifuzzaman, M., Haque, M.M., Zheng, Z., Washington, S. "Impact of mobile phone use on carfollowing behaviour of young drivers". Accid. Anal. Prev. 82, 10-19, 2015

[15] Neale, V.L., Dingus, T.A., Klauer, S.G., Sudweeks, J., Goodman, M. "An Overview of the 100car Naturalistic Study and Findings", National Highway Traffic Safety Administration. 2005

[16] Rohayu S., Sharifah Allyana S. M. R., Jamilah M.M., Wong S. V. "MRR 06/2012: Predicting Malaysian Road Fatalities for year 2020”. Malaysian Institute of Road Safety Research. 2012

[17] Jorgenson R. "Cost and Safety Effectiveness of Highway Design Elements". NCHRP Report 197, TRB, National Research Council, Washington, D. C. 1978.

[18] Zegeer C. V., Hummer J., Reinfurt D., Herf L., and Hunter W. "Safety effects of Cross-section Design for Two-Lane Roads: Volume 1". United States Federal Highway Administration. 1987

[19] Zegeer C. V., Hummer J., Reinfurt D., Hunter W., and Stewart R. "Accident Effects of Sideslope and Other Roadside Features on Two-Lane Roads". In Transportation Research Record I195, TRB, National Research Council, Washington, D.C. 1988.

[20] Ahmad Noor Syukri Z. A., Siti Atiqah M. F., Fauziana L. and Abdul Rahmat A. M. "MRR: MIROS Crash Investigation and Reconstruction Annual Statistical Report 2007-2010". MIROS Research Report. 05, 2012 
[21] Mak K. K., Sicking D. L. “Roadside Safety Analysis Program - Engineer's Manual”. National Cooperative Highway Research Program (NCHRP) Report 482. Transportation Research Board, Washington D.C. 2003

[22] Sicking D.L. and Ross H.E. "Benefit-cost Analysis of Roadside Safety Alternatives". Transportation Research Record. 1065, 98-105, 1986

[23] Lynam D. A., Kennedy J. V. "The Travel of Errant Vehicles After Leaving The Carriageway" Transport Research Laboratory, Published Project Report 298. 2008 